\title{
Xenocoelidia Kramer: descrição de uma espécie nova (Hemiptera, Auchenorrhyncha, Neocoelidiinae) ${ }^{1}$
}

\author{
Larissa de Bortolli Chiamolera ${ }^{2} \&$ Rodney R. Cavichioli ${ }^{2}$
}

${ }^{1}$ Contribuição número 1392 do Departamento de Zoologia, Universidade Federal do Paraná.

${ }^{2}$ Departamento de Zoologia, Universidade Federal do Paraná. Caixa Postal 19020, 81531-980 Curitiba, Paraná, Brasil. Bolsista CNPq. E-mail: larissachiamolera@bol.com.br; cavich@ufpr.br

\begin{abstract}
Xenocoelidia Kramer: description of a new species (Hemiptera, Auchenorrhyncha, Neocoelidiinae). A new species of Xenocoelidia Kramer, 1959 is described from Rio de Janeiro State, Brazil. This species can be distinguished by the aspect of the male genitalia, mainly by the aedeagus shape.
\end{abstract}

KEY WORDS. Auchenorrhyncha, Hemiptera, Neocoelidiinae, new species, Xenocoelidia.

Xenocoelidia foi descrito por Kramer (1959), o qual designou como espécie-tipo Xenocoelidia youngi Kramer, 1959 da Colômbia. $\mathrm{O}$ autor relacionou esse gênero a Chinaia Bruner \& Metcalf, 1934, os quais diferem na forma da fronte, na posição do ocelo, na forma do pigóforo do macho, dos estilos e do conetivo. Nesse mesmo trabalho, Kramer incluiu mais uma espécie: X. colombiana Kramer, 1959.

KRAMER (1964) transferiu mais uma espécie para o gênero: Neocoelidia inflata Osborn, 1923.

Kramer (1967) descreveu mais duas espécies: X. litura e $X$. charisma, apresentando uma chave para as espécies do gênero.

DeLong \& Kolbe (1975) descreveram X. spinella do Peru.

Atualmente, Xenocoelidia possuía seis espécies e, no presente trabalho, é proposta mais uma espécie, de Silva Jardim, Estado do Rio de Janeiro, a primeira com registro na região Sudeste do Brasil.

Os espécimes estudados estão depositados na coleção de entomologia "Pe. Jesus Santiago Moure" do Departamento de Zoologia da Universidade Federal do Paraná (DZUP).

As técnicas para o estudo das genitálias de machos seguem aquelas de Oman (1949), com pequenas alterações. A terminologia adotada na descrição da espécie é a mesma utilizada por KRAMER (1964), exceto para as estruturas da cabeça, a qual segue aquela proposta por Hamilton (1981) e sugerida por Mejdalani (1998).

\section{Xenocoelidia sexguttata sp. nov.} Figs 1-8

Holótipo macho. Brasil, Rio de Janeiro: Silva Jardim, III/ 1974, F.M. Oliveira leg. (DZUP). Alótipo: mesmos dados do holótipo, VIII/1975, F.M. Oliveira leg. (DZUP). Parátipo macho: mesmos dados do holótipo (DZUP).
Diagnose. Asas anteriores, cada uma com três pequenas manchas mais ou menos arredondadas ao longo da margem anal; edeago com ápice achatado e expandido, com vários pequenos espinhos e um par de processos pontiagudos no terço basal.

Medidas (em milímetros). Holótipo/Alótipo: comprimento total 6,08/6,67; comprimento mediano da cabeça $0,60 /$ 0,66; distância transocular 1,24/1,30; distância interocular 0,68/ 0,72 ; comprimento mediano do pronoto $0,56 / 0,54$; distância trans-humeral 1,48/1,66; largura máxima do escutelo 1,08/1,20; comprimento mediano do escutelo 0,80/0,92; comprimento das asas anteriores 4,80/5,42; largura máxima das asas anteriores $1,32 / 1,36$.

Cabeça, em vista dorsal, pronunciada; comprimento mediano metade da largura transocular; margem anterior levemente angulada, sem carena na transição entre a coroa e a face; superfície pontuada; ocelos localizados na margem anterior da coroa, evidentes, em vista dorsal; lóbulos supra-antenais, em vista dorsal, não protuberantes e, em vista lateral, oblíquos e carenados; fronte não intumescida e, em vista lateral, levemente arqueada; superfície pontuada; clípeo, em vista lateral, contínuo com a fronte e, em vista frontal, retangular. Pronoto mais largo que a cabeça; margens látero-anteriores convergentes anteriormente e carenadas; margens látero-posteriores convergentes posteriormente; margem posterior com uma reentrância mediana; superfície lisa. Escutelo levemente pontuado. Asas anteriores aproximadamente quatro vezes mais longas que largas; venação obscura, exceto apicalmente; com três células apicais; apêndice curto, estendendo-se até a metade da segunda célula apical. Pigóforo mais ou menos retangular; comprimento mais de duas vezes a sua largura basal; sem processos; margem apical truncada, com uma pequena projeção pontiaguda no terço basal; porção ventro-apical com espessamento da cutícula. Placas subgenitais fundidas até o terço apical; base muito mais 


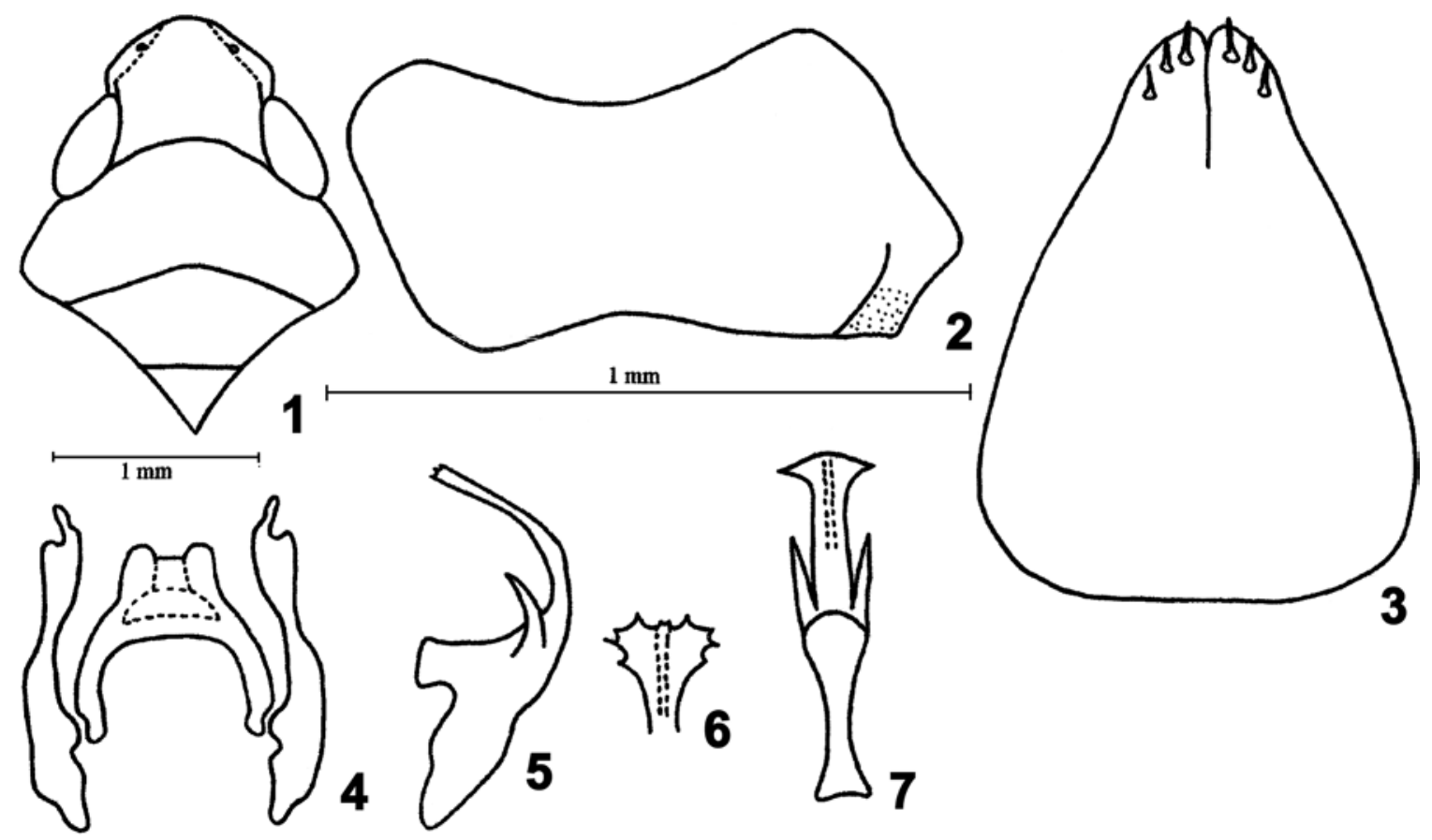

Figuras 1-8. Xenocoelidia sexguttata sp. nov.: (1) cabeça, pronoto e escutelo, vista dorsal; (2) pigóforo, vista lateral; (3) placas subgenitais, vista ventral; (4) estilos e conetivo, vista dorsal; (5) edeago, vista lateral; (6) ápice do edeago, vista dorsal; (7) edeago, vista dorsal.

larga que o ápice; porção apical com algumas cerdas. Estilos com pequena projeção caudal e ápice estreitado curvado para fora. Conetivo em forma de "U" invertido, com região central menos esclerotinizada. Edeago alargado basalmente, afilandose em direção ao ápice, curvado para cima a partir da metade apical; com um par de processos afilados e pontiagudos no terço basal; ápice achatado e expandido lateralmente, com curtos espinhos.

Coloração. No geral amarelada, apenas com três manchas marrons na margem anal de cada uma das asas anteriores.

Comentários. Xenocoelidia sexguttata sp. nov. é similar a X. spinella DeLong \& Kolbe, 1975, no aspecto do edeago, diferindo pela presença de apenas uma projeção apical e pelo par de processos no terço basal.

Etimologia. O nome da espécie é alusivo às três manchas marrons em cada uma das asas anteriores.

\section{AGRADECIMENTOS}

Agradecemos ao Conselho Nacional de Desenvolvimento Científico e Tecnológico (CNPq), pelo auxílio concedido referente ao processo 475565/01-0, bolsa de mestrado e Produtividade em Pesquisa.

\section{REFERÊNCIAS BIBLIOGRÁFICAS}

DeLong, D.M. \& A.B. Kolbe. 1975. Three new species of Neocoelidiinae (Homoptera-Cicadellidae) from Panama and Peru. Journal of the Kansas Entomological Society, Lawrence, 48 (1): 124-126.

Revista Brasileira de Zoologia 20 (2): 199-200, junho 2003
HamiLton, K.G.A. 1981. Morphology and evolution of the rhynchotan head (Insecta: Hemiptera, Homoptera). Canadian Entomologist 113 (11): 953-974.

Kramer, J.P. 1959. An elucidation of the neotropical genus Chinaia with a key to males and a new allied genus (Homoptera: Cicadellidae: Neocoelidiinae). Proceedings of the Biological Society of Washington 72: 23-32.

.1964. A generic revision of the leafhopper subfamily Neocoelidiinae (Homoptera: Cicadellidae). Proceedings of the United States National Museum, Washington,D.C., 115 (3484): 259-287.

-1967. New neotropical Neocoelidiinae with keys to the species of Coelidiana, Xenocoelidiana, and Nelidina (Homoptera:Cicadellidae). Proceedings of the Entomological Society of Washington 69 (1): 31-46.

Mejdalani, G. 1998. Morfologia externa dos Cicadellinae (Homoptera: Cicadellidae): comparação entre Versigonalia ruficauda (Walker) (Cicadellini) e Tretogonia cribrata (Melichar) (Proconiini), com notas sobre outras espécies e análise da terminologia. Revista Brasileira de Zoologia, Curitiba, 15 (2): 451-544.

Oman, P.W. 1949. The Nearctic leafhoppers (Homoptera: Cicadellidae). A generic classification and check list. Memoirs of the Entomological Society of Washington 3: 1-253.

Recebido em 21.X.2002; aceito em 13.V.2003. 